James Madison University JMU Scholarly Commons

Masters Theses

The Graduate School

Spring 2013

\title{
The implications of undiagnosed obstructive sleep apnea on resting hemodynamic variables in cardiac rehabilitation patients
}

Brooke Marie Shafer

James Madison University

Follow this and additional works at: https://commons.lib.jmu.edu/master201019

Part of the Kinesiology Commons

\section{Recommended Citation}

Shafer, Brooke Marie, "The implications of undiagnosed obstructive sleep apnea on resting hemodynamic variables in cardiac rehabilitation patients" (2013). Masters Theses. 322.

https://commons.lib.jmu.edu/master201019/322

This Thesis is brought to you for free and open access by the The Graduate School at JMU Scholarly Commons. It has been accepted for inclusion in Masters Theses by an authorized administrator of JMU Scholarly Commons. For more information, please contact dc_admin@jmu.edu. 
The Implications of Undiagnosed Obstructive Sleep Apnea on Resting Hemodynamic Variables in Cardiac Rehabilitation Patients.

\author{
Brooke Shafer
}

A thesis project submitted to the Graduate Faculty of

\title{
JAMES MADISON UNIVERSITY
}

\author{
In \\ Partial Fulfillment of the Requirements \\ for the degree of \\ Master of Science
}

Kinesiology

May 2013 


\section{Acknowledgements}

I would first like to thank Dr. Trent Hargens for all the time and effort he put into helping me with my Master's thesis and working directly with me as my thesis advisor. I am thankful that he gave me the opportunity to work with him on this project and I am appreciative for the dedication he put into seeing this study succeed.

I would like to thank Dr. Adrian Aron, from Radford University, for combining his database with our own database. This allowed for a much larger sample size to analyze, for which I am truly grateful.

I would like to thank Dr. Christopher Womack and Dr. Elizabeth Edwards for serving as members of my thesis committee. Your input and support were greatly appreciated.

I would finally like to thank Kate Guerriere, Nichole Hafner, Sarah Jacoby, and Taylor Wenos for the overall support over the past year. 


\section{Table of Contents}

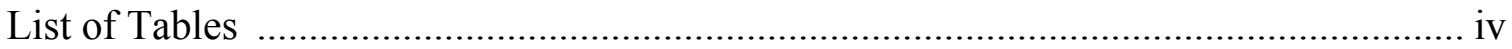

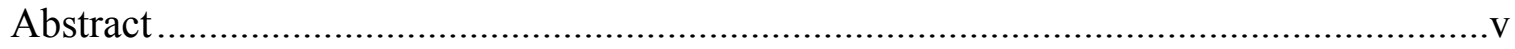

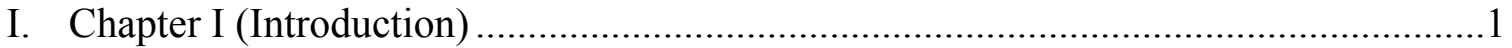

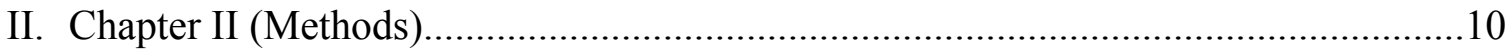

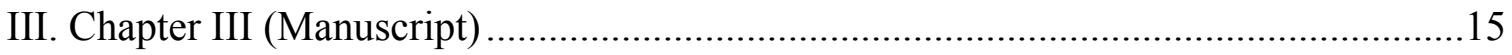

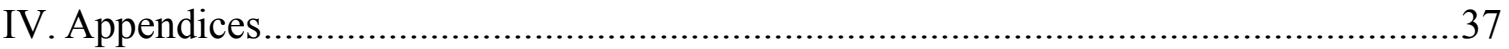

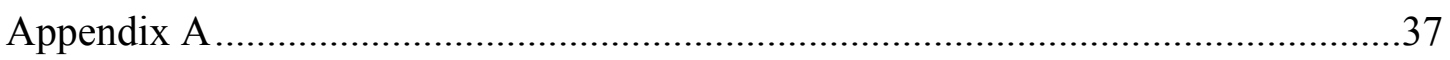

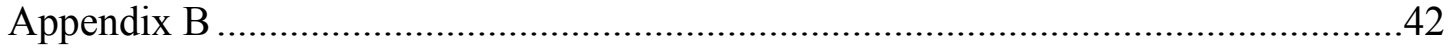

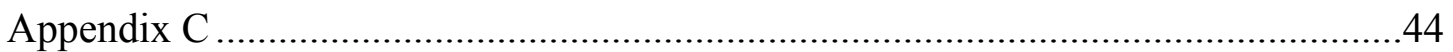

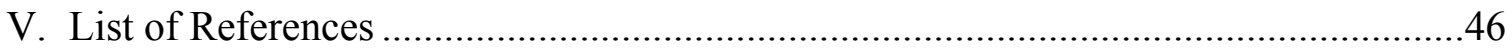




\section{List of Tables}

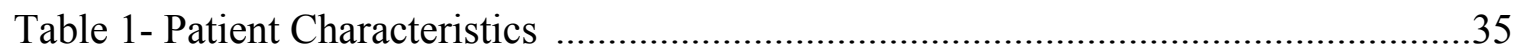

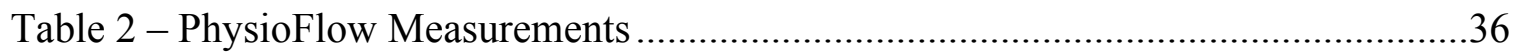




\section{Abstract}

The primary objective of this study was to examine the effects of obstructive sleep apnea (OSA) on resting hemodynamic variables pre- and post-cardiac rehabilitation

(CR). Subjects were screened for OSA using an at-home screening device. Subjects were then divided into two design groups: subjects with likely OSA (OSA) and subjects without OSA (non-OSA). All patients had resting hemodynamic measurements recorded and performed a 6-minute walk test. Resting hemodynamics and 6-minute walk test were performed pre- and post-CR. The study was conducted at Rockingham Memorial Hospital in Harrisonburg, VA and Carilion Roanoke Community Hospital in Roanoke, VA where subjects completed standard early-outpatient (Phase II) Cardiac Rehabilitation. The sample consisted of 33 OSA subjects (age: $65.0 \pm 12.4$ years; AHI: $17.2 \pm 12.3$ ) and 12 non-OSA subjects (age: $63.7 \pm 11.2$ years; AHI: $1.8 \pm 1.3$ ). Both the OSA and the nonOSA group had a significant improvement in BMI $(p=0.046)$ from baseline measurements to follow-up without a significant difference between groups. Both groups significantly improved 6-minute walk test performance $(\mathrm{p}<0.0001)$ from baseline to follow-up, with the OSA group having significantly higher values at both time points. The OSA group had significantly lower cardiac index values $(\mathrm{p}=0.018)$, ejection fraction values $(p=0.039)$, and contractility index values $(p=0.008)$ when compared to the non OSA group at baseline and follow-up. The OSA group had significantly higher systemic vascular resistance index values $(\mathrm{p}=0.027)$ when compared to the non-OSA group at baseline and follow-up. There was no significant effect for time or group by time with respect to any other variable. CR can facilitate in BMI improvement, while potentially improving 
cardiovascular fitness in patients. CR did not improve resting hemodynamic variables, regardless of OSA presence. However, subjects with OSA appear to have diminished cardiac function when compared to non-OSA subjects, manifesting through increased systemic vascular resistance index and decreased contractility index, cardiac index, and ejection fraction. 


\section{Chapter One}

\section{Introduction}

Obstructive sleep apnea (OSA) is a sleep disorder that affects roughly $3 \%$ to $7 \%$ of men and $2 \%$ to $5 \%$ of women in the general population; however prevalence is reported to be higher among overweight and obese populations [1]. It is estimated that 1 in every 5 adults have at least mild OSA and 1 in every 15 adults have at least moderate OSA when body mass index (BMI) measurements range between 25 and $28 \mathrm{~kg} / \mathrm{m}^{2}$ [2]. OSA is characterized by recurring episodes of complete or near complete collapse of the upper-airway during sleep [2]. An apneic event is a complete obstruction of the upperairway that causes a pause in respiration for a duration of $\geq 10$ seconds. Apnea is associated with continued ventilatory effort and, when terminated, is followed by an arousal from sleep [2]. A hypopnea is a partial airway obstruction that results in a $<50 \%$ reduction in airflow, is associated with a reduction in oxyhemoglobin saturation, and is often followed by sleep arousal [3]. Disease severity is measured on an apnea-hypopnea index (AHI), which measures the frequency of apneas and hypopneas per hour of sleep [3].

The prevalence and progression of OSA severity in the general population has been shown to have a strong positive association with age and BMI, with male sex, weight, neck size, and visceral adiposity being additional risk factors [3-7]. The presence of OSA, alone, can be detrimental to an individual's health; but more serious health implications may occur if the disease works congruently with other cardiovascular disease (CVD) manifestations. When adjusted for known OSA risk factors, epidemiological evidence suggests a causal relationship between the presence of OSA 
and CVD development [8]. Not only is OSA present in roughly $50 \%$ of patients with hypertension, but it has also been identified as an independent risk factor for developing hypertension [8-10]. It is estimated that in patients with coronary artery disease, roughly $30 \%$ have OSA [8]. Furthermore, patients who experience a nocturnal myocardial infarction (MI) have a high likelihood of having OSA, suggesting that the presence of OSA may be a trigger for a MI [11]. Investigative studies on patients who experience a MI report that the prevalence of OSA ranges anywhere from $65.7 \%$ to $91 \%$ [11-13]. In heart failure patients the prevalence of OSA ranges from $12 \%$ to $53 \%$ [8].

The severity of OSA has a strong association with CVD risk and all cause mortality [14-18]. This risk of CVD is mediated through the chronic exposure to intermittent vascular and hemodynamic fluctuations that occur during nocturnal apneic events. The majority of OSA patients have smaller anatomical airways, either due to a large neck circumference [19] or obesity [3]. Both factors contribute to the collapsibility of the upper-airway during sleep. The upper airway is regulated by dilator muscles that reflexively respond to changes in intrathoracic pressure. Reductions in airway size result in an increase in airway resistance and an increase in intrathoracic negative pressure during inspiration $[3,20]$. In the awakened state, dilator muscle activation compensates for the airway resistance; however, dilatory muscle activation is significantly attenuated during sleep. In normal subjects, this results in a small degree of airflow resistance. In subjects with OSA, the reduction of reflex driven dilator activity leads to intermittent complete or near-complete collapse of the upper airway $[3,20]$.

Peripheral chemoreceptors, located in the carotid bodies, primarily respond to fluctuations in blood oxygen retention. During apneas, oxyhemoglobin desaturation 
stimulates peripheral chemoreceptor activity to increase sympathetic discharge, which progressively increases with desaturation $[2,21,22]$. The increase in sympathetic nerve activity is accompanied by a rise in plasma norepinephrine levels (NE), peripheral vasoconstriction, mean arterial pressure, heart rate, and blood pressure [21-23].

Continued ventilatory efforts to inspire against the narrowed or collapsed airway results in increased intrathoracic negative pressure and hemodynamic alterations [24]. The cessation of breathing and the increase in intrathoracic negative pressure decreases venous return, impairs left ventricular (LV) relaxation, and hinders LV filling [21, 25]. The increase in intrathoracic negative pressure is also associated with an increase LV transmural pressure and causes an increase in LV afterload [26]. The increase in peripheral resistance contributes to the increase in LV afterload, resulting in the heart having to work against a greater pressure with each beat $[22,26]$. The combination of decreased cardiac preload and increased cardiac afterload results in a decrease in stroke volume and cardiac output during apnea [25]. The peripheral vasoconstriction helps, in part, to maintain blood pressure and venous return during the obstruction [21]; however, compared to baseline values, there is an overall decrease in cardiac output and cardiac index; cardiac index being cardiac output in relation to body surface area [27]. The acute physiological fluctuations that occur during apneas are analogous to hypopneas [2]. Apneas and hypopneas are terminated by central nervous system arousals that activate the upper airway dilator muscles [25]. The resumption of breathing results in a withdrawal of sympathetic discharge, an increase in venous return, temporary tachycardia, and a significant increase in cardiac output and cardiac index [21,27]. The increase in 
cardiac output and the surge of blood flow against vasoconstricted arteries causes transient spikes in blood pressure that can reach levels as high as 240/130 $\mathrm{mmHg}$ [21]. If left untreated, the apneic episodes associated with OSA can lead to vascular and cardiac alterations. The presence of OSA appears to be predominately responsible for endothelial dysfunction [28]. Patients with OSA have increased nighttime and daytime sympathetic nerve activity when compared to normal controls, [21, 23], which is associated with an increase in plasma NE levels [23]. The increase in sympathetic activity and NE is associated with an increase in vasoconstriction [29]. Furthermore, circulating levels of nitric oxide (NO), a potent vasodilator, are suppressed in patients with OSA [30, 31]. Chronic exposure of increased pressure on the endothelium could lead to a decrease in NO biosynthesis and, therefore, endothelial dysfunction [31]. OSA can activate inflammatory pathways that can lead to an increase in oxidative stress and a chronic systemic low-grade inflammatory state in patients, regardless of body fat percentage [28, $32,33]$. Chronic exposure to oxidative stress and inflammation can lead to endothelial damage. Finally, patients with OSA have been shown to have higher circulating levels of prothrombotic biomarkers [34]. Circulating levels of plasminogen activator inhibitor type-1 and fibrinogen have been recorded in patients with OSA and have a positive association with AHI [34]. These biomarkers are further indicators of endothelial dysfunction and create a chronic prothrombotic state. Endothelial dysfunction increases the risk of hypertension, atherosclerotic lesion development, cardiac ischemia, coronary artery damage, MI, heart failure, or sudden death [3, 32, 35, 36].

Repetitive surges in blood pressure upon the cessation of apnea may lead to sustained systemic hypertension and contribute to cardiac adaptations $[8,14,16]$. Clinical 
implications of chronic exposure to intrathoracic pressure changes and large spikes in blood pressure are cardiac remodeling and ventricular dysfunction. Independent of other disease manifestations, OSA can impair LV relaxation, which may be a consequence of the intermittent cardiac overload during apneic events [37]. Other cardiac abnormalities are observed as OSA severity progresses. Severe OSA is associated with increased incidence of LV hypertrophy. This may be due to the increased transmural pressure, hypoxemia, and increased sympathetic nervous system activity that occur during nocturnal obstructive apneas. LV hypertrophy may also manifest from the high afterload that is associated with sustained hypertension, which is also common amongst OSA patients [38]. Other cardiac manifestations associated with increasing disease severity are left atrial enlargement, right atrial enlargement, and right ventricular hypertrophy; however, even in the presence of these structural abnormalities, ejection fraction appears to be maintained $[38,39]$. Nonetheless, these structural adaptations do influence the risk for cardiac arrhythmias [40, 41], the risk of congestive heart failure [39], and the risk of sudden death [42]. It is the combination of these physiological alterations that make OSA an important risk factor for CVD morbidity.

Recent data suggests that about $53 \%$ of patients entering a cardiac rehabilitation (CR) program are at high risk for having OSA and, of that $53 \%, 43 \%$ of those patients may be undiagnosed and untreated [43]. Reasons for entering a CR program could range from MI, coronary artery bypass graph surgery, percutaneous coronary intervention, cardiac transplant, chronic heart failure, or cardiac valve repair or replacement [44]. CR programs significantly reduce the risk of a secondary fatal MI, mortality from coronary artery disease, and overall mortality through exercise-related health gains $[45,46]$. 
Exercise training provided by a CR program is beneficial for decreasing blood coagulability, the ability to form clots, as well as increasing fibrinolysis, the mechanism that breaks down clot formation; these adaptations thereby decrease the overall risk of thrombosis [44]. Exercise training improves the inflammatory state of patients by decreasing inflammatory markers such as C-Reactive protein [47]. Ultimately, the reduction in inflammation can improve endothelial function, in addition to exercise related gains in endothelium- dependent vasodilation [44]. Additional benefits of exercise training include attenuated hyperactivity of the sympathetic nervous system, improved exercise and functional capacity levels, improved lipid profiles, moderate reduction in weight and adiposity, improved submaximal heart rate levels, and improved systolic blood pressures [44-46]. These benefits reduce the risk of a secondary coronary event and overall mortality.

Patients entering a CR program may perform a symptom limited exercise capacity test to evaluate current fitness levels. Patients with OSA show altered cardiopulmonary response during exercise testing, which could indicate disease specific alterations to exercise capacity. When compared to normal controls, middle-aged OSA patients show elevated systolic and diastolic blood pressures during exercise testing [48-50] and an attenuated decline in systolic blood pressure during active recovery [48]. This may be a result of increased peripheral resistance [50], although this finding has not been confirmed in younger subjects with OSA [51]. Attenuated HR recovery has been observed in OSA patients post exercise [51-53], which is an independent predictor of allcause mortality [54]. 
In normotensive OSA subjects with normal resting LV function, OSA subjects had lower cardiac output and stroke volume responses to exercise when compared to control patients [55]. However, this response to exercise was improved after 3 months of continuous positive airway pressure therapy, suggesting that there is a relationship between the presence of OSA and LV impairment during exercise [55]. Finally, patients with OSA have been shown to have significantly lower lactate levels at maximal exercise and a slower lactate removal rate during recovery when compared to control patients. The lower levels of maximal blood lactate may suggest impaired glycolytic metabolism during exercise and the delayed lactate removal rate may suggest impaired oxidative metabolism post exercise [50].

Patients with OSA can safely participate in prolonged exercise training programs and experience a decrease in disease severity. OSA patients regularly participating in exercise training have reported significant improvements in subjective feelings of fatigue, tension, physical functioning, and overall health perception [56]. With exercise training, significant improvements have been reported in sleep efficiency, sleep onset latency, and reduced OSA severity, regardless of reductions in body weight $[57,58]$. The goal of these interventions was to observe the effects of exercise on disease severity; however, the effects of exercise training on hemodynamic adaptations in patients with OSA were not measured.

The literature is mixed in regards to resting hemodynamic variables between patients with OSA and patients without. In the absence of CVD, subjects with OSA have been reported to have LV systolic and diastolic dysfunction, shown through lowered LV ejection fractions, reduced LV peak emptying rate, and reduced LV peak filling rate [59, 
60]. However, normal ejection fraction values have been reported in subjects with severe OSA [38]. Some report significantly higher resting heart rate values in patients with OSA when compared to control patients [53], although no difference between groups has also been reported [23]. There appears to be no difference in stroke volume index and cardiac index between OSA and control patients [48]. Some studies report an increase in resting systolic blood pressure in patients with OSA [48] and some report no difference [55].

Exercise programs for patients in $\mathrm{CR}$ are beneficial for increasing exercise capacity and improving hemodynamic variables. In patients diagnosed with OSA, in the absence of existing CVD morbidities, the literature is mixed regarding resting hemodynamic variables. Resting hemodynamics may be exaggerated between patients with OSA and without OSA in a CR program, where other comorbidities are present. Both patients with OSA and patients without OSA can see cardiopulmonary benefits from a structured exercise program. However, pressure and volume fluctuations that occur during apneas may attenuate the hemodynamic improvements a patient with untreated OSA may experience from a CR program when compared to patients without OSA.

\section{Purpose}

The purpose of this study is to examine the effects of untreated OSA on resting hemodynamic variables pre- and post-CR. It is hypothesized that subjects with undiagnosed and untreated OSA will see attenuated hemodynamic improvements following CR when compared to subjects without OSA. 


\section{Assumptions}

For the duration of the study, it is assumed that subjects will consistently and routinely take part in the CR program and that the conditions outside the scope of the study will remain consistent.

\section{Delimitations}

Subjects will be limited to CR patients at Rockingham Memorial Hospital and Carilion Roanoke Community Hospital. Subjects will be screened for OSA with an at home screening device.

\section{Limitations}

Subjects will have 1 week upon CR entry to decide if they want to participate in the study. In addition, subjects will not be excluded based on current medication use.

\section{Definition of Terms}

Mild OSA: AHI of 5-15[2, 7]

Moderate OSA: AHI of 15-30 [2, 7]

Severe OSA: AHI of 30 or greater $[2,7]$ 


\section{Chapter II}

\section{Methodology}

The purpose of this study was to examine the relationship between the presence of OSA in patients with cardiovascular disease on resting hemodynamic variables in a cardiac rehabilitation (CR) setting. This study has received the International Review Board approval at James Madison University, at Rockingham Memorial Hospital, and at Carilion Roanoke Community Hospital.

\section{Subjects}

Subjects consisted of patients recently admitted into the Rockingham Memorial Hospital and the Carilion Roanoke Community Hospital Cardiac Rehabilitation programs. All subjects were informed of the study during the CR orientation visit by either the clinical exercise physiologist or the nursing staff. If interested in the study, subjects were sent home with Informed Consent documentation and an Epworth Sleepiness Scale (ESS). All subjects were patient volunteers. The study consisted of 45 subjects, 32 males and 13 females. Age of the subjects ranged from 30 to 84 years, with a mean $( \pm \mathrm{SD})$ age of $45 \pm 12$ years. Subject characteristics are described in detail in Table 1. The study had two exclusion criteria: subjects who had diagnosed pulmonary disease and/or subjects who were currently being treated for OSA were excluded from the study. There were no other exclusion criteria on the basis of age, gender, or health history.

\section{Procedures}

Baseline Assessment

On the first day of CR, subjects returned with their completed Informed Consent and ESS. The ESS conist of eight situations that are likely to evoke daytime sleepiness 
for the respondent. Responders are asked to rank the likelihood of dozing off during the eight situations on a scale from $0-3$, with 0 indicating "never dozes" and 3 indicating a "high chance of dozing." The scores are then added together to give a score between 0 and 24, which corresponds to low levels of daytime sleepiness and high levels of daytime sleepiness, respectively. The ESS has been shown to distinguish normal patients from patients with various sleep related disorders, such as OSA, narcolepsy, and idiopathic hyperinsonmia [61]. In patients with OSA, a significant correlation has been reported between ESS scores, respiratory disturbance index, and minimium oxyhemoglobin saturation levels, confirmed through overnight polysomnography [61].

Subject height was measured with a stadiometer and weight was measured with an electronic scale. Body mass index (BMI) was calculated by converting weight into kilograms and height into meters, then using the equation: $\mathrm{BMI}=$ weight $(\mathrm{kg}) /$ height $(\mathrm{m})$ ${ }^{2}$. Resting blood pressure was measured manually using a sphygmomanometer and a stethoscope while the subject was in supine position.

Sex, age, weight, height and resting blood pressure were manually entered into the PhysioFlow software and resting PhysioFlow measurements were recorded for 10 minutes while subjects were in the supine position. The PhysioFlow (PhysioFlow PF-05 Lab1, NeuMeDx, Bristol, PA) is non-invasive, impedance cardiograph that measures various hemodynamic parameters. The PhysioFlow measures heart rate, stroke volume, cardiac output, cardiac index, contractility index, systolic arterial pressure, diastolic arterial pressure, ejection fraction, left ventricular ejection time, end diastolic volume, systemic vascular resistance, and systemic vascular resistance index. The device consists of 6 PhysioFlow Skintact pre-gelled Ag/AgCl electrodes, a 6-lead ECG cable connector, 
and is compatible with Microsoft Windows 2000 XP or a later operating system. Subjects need to be prepped with alcohol pads and attached with the 6 pre-gelled electrodes. Initiation of a 30-beat calibration cycle begins continuous hemodynamic data collection. The electrodes, placed on the neck and chest, detect electrical and impedance changes in the thorax, which are used to measure and calculate the hemodynamic parameters. The PhysioFlow has been validated to provide clinically acceptable, non-invasive evaluation of cardiac performance [62].

All subjects performed a 6-minute walk test after resting PhysioFlow measurements were recorded. The distance each subject walked in 6 minutes was measured in feet. Heart rate and rating of perceived exertion were recorded every minute of the test. Following the 6-minute walk test, subjects sat in a chair for a 5-minute recovery period while heart rate and blood pressure were measured every minute of recovery. The 6-minute walk test is a reliable and valid measure of cardiovascular endurance in the elderly [63].

After the 5-minute recovery, subjects were given an at-home apnea screening device (ApneaLink Plus, ResMed Corp., San Diego, CA) to screen for possible OSA. The device consists of an adjustable Velcro belt that holds in place a respiratory effort sensor, a nasal cannula, and a pulse oximeter. The ApneaLink Plus measures respiratory nasal airflow, snoring, blood oxygen saturation, heart rate, and respiratory effort during sleep. The Apnealink Plus records partial or complete respiratory obstructions, duration of obstructions, lowest and highest heart rate measurements, lowest and highest blood oxygen saturation measurements, and the time points that these events occur during sleep. The ApneaLink Plus provides a reliable initial assessment of suspected OSA [64]. A copy 
of instructions on how to use the ApneaLink Plus was sent home with the subject. In addition, an accelerometer (ActiGraph GT3X+, ActiGraph, Pensacola, FL) was given to the subjects with instructions on its use. The accelerometer is a device that detects and measures movement during sleep while being worn on the non-dominant wrist. The accelerometer records the time of sleep onset, total sleep time, total awake time, number of awakenings, and the average duration of awakenings. Data was downloaded on to a computer and analyzed with proprietary software. These devices have been validated relative to measures obtained through polysomnography $[65,66]$.

ApneaLink reports were sent to a certified sleep technician to analyze the data. Based on the technician report, subjects were divided into either an OSA group or a nonOSA group. Subjects were assigned to the OSA group if AHI $\geq 5$. Of the 45 subjects, 33 were classified as OSA and 12 were classified as non-OSA. All subjects then participated in scheduled CR sessions at their respective hospital. Subjects completed an average of $25.6 \pm 8.4 \mathrm{CR}$ sessions. The average stay in CR was between 2-3 months, with the least being 1 month and the most being 4 months. CR staff was blinded to the group designation of each patient. Follow-up Assessment

On the subjects' last day of CR participation, all hemodynamic variables were reassessed and the 6-minute walk test was repeated.

\section{Statistical Analysis}

The statistical analysis program used for this study was the IBM SPSS Statistics version 20. A mixed design ANOVA analysis was used to analyze mean values of weight, BMI, physioflow variables, and 6-minute walk test results from baseline to follow-up. 
Group was the between subject factor (OSA and non-OSA) and time was the withinsubject factor (baseline and follow-up). In cases where significance was found for the Mauchly's test of sphericity (cardiac index, ejection fraction, contractility index, and systemic vascular resistance), the Greenhouse-Geisser correction factor was used to adjust the $F$-test accordingly and its significance accordingly. All data are presented mean \pm the standard deviation. The statistical significance for all tests was set $a$ priori at $p<0.05$. 


\section{Chapter III}

\section{Journal Manuscript}

Journal Format: Sleep and Breathing

Manuscript Title: The Implications of Undiagnosed Obstructive Sleep Apnea on Resting Hemodynamic Variables in Cardiac Rehabilitation Patients.

\section{ABSTRACT}

Study Objective: The primary objective of this study was to examine the effects of obstructive sleep apnea (OSA) on resting hemodynamic variables pre- and post-cardiac rehabilitation (CR).

Design: Subjects were screened for OSA using an at-home screening device. Subjects were then divided into two design groups: subjects with likely OSA (OSA) and subjects without OSA (non-OSA). All patients had resting hemodynamic measurements recorded and performed a 6-minute walk test. Resting hemodynamics and 6-minute walk test were performed pre- and post-CR.

Setting: The study was conducted at Rockingham Memorial Hospital in Harrisonburg, VA and Carilion Roanoke Community Hospital in Roanoke, VA.

Participants: 33 OSA (age: $65.0 \pm 12.4$ years; AHI: $17.2 \pm 12.3$ ) and 12 non-OSA (age:

$63.7 \pm 11.2$ years; AHI: $1.8 \pm 1.3)$.

Intervention: Standard early-outpatient (Phase II) CR.

Measurements and Results: Both the OSA and the non-OSA group had a significant reduction in BMI $\left(\mathrm{OSA}=-0.31 \mathrm{~kg} / \mathrm{m}^{2} ;\right.$ non-OSA $\left.=-0.36 \mathrm{~kg} / \mathrm{m}^{2}\right)$ from baseline measurements to follow-up without a significant difference between groups. Both groups significantly improved 6-minute walk test performance $(\mathrm{OSA}=+322.86 \mathrm{ft}$; non-OSA $=$ 
$+212.87 \mathrm{ft}$ ), with the OSA group having significantly higher values at both time points $(\mathrm{p}=0.018)$. When compared to the non-OSA group, the OSA group had significantly lower values at both baseline and follow-up for cardiac index $\left(2.1 \mathrm{~L} / \mathrm{min} / \mathrm{m}^{2}\right.$ and 2.2 $\mathrm{L} / \mathrm{min} / \mathrm{m}^{2}$ vs. $2.6 \mathrm{~L} / \mathrm{min} / \mathrm{m}^{2}$ and $2.6 \mathrm{~L} / \mathrm{min} / \mathrm{m}^{2}$; baseline and follow-up, OSA vs. non-OSA, respectively, $p=0.018)$, ejection fraction $(57.2 \%$ and $59.6 \%$ vs. $65.4 \%$ and $65.4 \%$; baseline and follow-up, OSA vs. non-OSA, respectively, $p=0.039$ ), and contractility index (105.2 and 127.8 vs. 162.1 and 160.7; baseline and follow-up, OSA vs. non-OSA, respectively, $p=0.008$ ). When compared to the non-OSA group, the OSA group had significantly higher values at both baseline and follow-up for systemic vascular resistance index (3730.2 dyn $\cdot \mathrm{s} / \mathrm{cm}^{5}$ and $3357.2 \mathrm{dyn} \cdot \mathrm{s} / \mathrm{cm}^{5}$ vs. $2690.2 \mathrm{dyn} \cdot \mathrm{s} / \mathrm{cm}^{5}$ and 2660.8 dyn $\cdot \mathrm{s} / \mathrm{cm}^{5}$; baseline and follow-up, OSA vs. non-OSA, respectively, $\left.p=0.027\right)$. There was no significant effect for time or group by time with respect to any other variable. Conclusions: $\mathrm{CR}$ can facilitate in BMI improvement, while potentially improving cardiovascular fitness in patients. CR did not improve resting hemodynamic variables, regardless of OSA presence. However, when standardizing for body surface area, subjects with OSA appear to have diminished cardiac function when compared to nonOSA subjects.

Key Words: Obstructive sleep apnea, hemodynamics, cardiac rehabilitation 


\section{INTRODUCTION}

Obstructive sleep apnea (OSA) is a sleep disorder that affects roughly $3 \%$ to $7 \%$ of men and $2 \%$ to $5 \%$ of women in the general population; however, prevalence is reported to be higher among the overweight and obese[1]. It is estimated that 1 in every 5 adults have at least mild OSA and 1 in every 15 adults have at least moderate OSA when body mass index (BMI) measurements range between 25 and $28 \mathrm{~kg} / \mathrm{m}^{2}$ [2]. OSA is characterized by recurring episodes of complete (apnea) or near complete (hypopnea) collapse of the upper-airway during sleep [2].

Hypopneas occur when there is a partial collapse of the airway, resulting in a $<50 \%$ reduction in airflow and is usually associated with a reduction in oxyhemoglobin saturation [3]. An apnea is a complete collapse of the airway followed by continued ventilator effort [3]. Hypopneas and apneas create a hypoxemic environment that is associated with an incremental increase in sympathetic nerve activity accompanied by a rise in plasma norepinephrine levels, peripheral vasoconstriction, mean arterial pressure, heart rate, and blood pressure [2, 4-6]. The continued ventilatory efforts against a narrowed or collapsed airway result in increased intrathoracic negative pressure and hemodynamic alterations $[2,7]$. Apneas and hypopneas are terminated by central nervous system arousals $[7,8]$. The resumption of breathing results in a withdrawal of sympathetic discharge, an increase in venous return, temporary tachycardia, and a significant increase in cardiac output $(\mathrm{CO})$ and cardiac index (CI) $[4,9]$. The increase in $\mathrm{CO}$ and the surge of blood flow against vasoconstricted arteries causes transient spikes in blood pressure (BP) that can reach levels as high as 240/130 $\mathrm{mmHg}$ [4]. OSA has been identified as an independent risk factor for developing hypertension [10] and coronary 
artery disease [8], in addition to increasing the risk for myocardial infarction (MI) [3], congestive heart failure [11], and an increase in all cause mortality [12].

Recent data suggests that about $53 \%$ of patients entering a cardiac rehabilitation (CR) program are at high risk for having OSA and, of that $53 \%, 43 \%$ of those patients may be undiagnosed and untreated [13]. CR programs significantly reduce the risk of a secondary fatal MI and all-cause mortality through exercise-related health gains $[14,15]$. Exercise training provided by a CR program can benefit patients by decreasing the risk of thrombosis, improving inflammatory markers, improving exercise and functional capacity levels, improving lipid profiles, providing moderate reductions in weight and adiposity, improving submaximal heart rate (HR) levels, and improving systolic BP [14$16]$.

Patients with OSA can safely participate in progressive and prolonged exercise training programs without adverse affects and see improvements in disease severity [1719] . OSA patients regularly participating in exercise training have reported significant improvements in subjective feelings of fatigue, physical functioning [20], and reduced OSA severity, regardless of reductions in body weight [17]. However, the effects of exercise training on hemodynamic adaptations in patients with OSA have not been measured.

Patients with OSA show altered cardiopulmonary responses to acute exercise testing, which may indicate disease specific alterations to exercise capacity. When compared to normal controls, middle-aged OSA patients show elevated systolic and diastolic BP during exercise testing [21-23] and an attenuated decline in systolic BP during active recovery [21], although this finding has not been confirmed in younger 
subjects with OSA [24]. Attenuated HR recovery has been observed in OSA patients post exercise [24-26], which is an independent predictor of all-cause mortality [27].

The literature is mixed in regards to resting hemodynamic variables between patients with and without OSA. Subjects with OSA have been reported to have left ventricular (LV) systolic and diastolic dysfunction, as indicated by lowered LV ejection fractions (EF), reduced LV peak emptying rate, reduced LV peak filling rate [28, 29]. However, normal EF values have been reported in subjects with severe OSA [30]. Some report significantly higher resting HR values in patients with OSA when compared to control patients [26]; although no difference between groups has also been reported [5]. Current literature indicates no difference in stroke volume (SV) index and CI between OSA and control patients $[11,21]$. Some studies report an increase in resting systolic BP in patients with OSA [21], while others report no difference [31]. Subjects from these previous studies, however, were all subjects with OSA but without evidence of CVD.

The difference in resting hemodynamic variables may be exaggerated between patients with OSA and patients without OSA in a CR program, where other comorbidities are present. Both patients with OSA and patients without OSA can see cardiopulmonary benefits from a structured exercise program. The adverse health implications of the presence of OSA may attenuate the cardiovascular and hemodynamic improvements a patient with untreated OSA may experience from a CR program when compared to patients without OSA.

The purpose of this study is to examine the relationship between OSA and CR outcomes on resting hemodynamic variables in patients with cardiovascular disease. It is 
hypothesized that patients with undiagnosed OSA will see attenuated cardiovascular and hemodynamic improvements following CR compared to their non-OSA counterparts. MATERIALS AND METHODS

Subjects

Subjects consisted of patients recently admitted into the Rockingham Memorial Hospital and the Carilion Roanoke Community Hospital Cardiac Rehabilitation programs. All patients were informed of the study during the CR orientation visit by CR staff. If interested in the study, patients were sent home with Informed Consent documentation and an Epworth Sleepiness Scale (ESS). All subjects were patient volunteers. The study consisted of 45 subjects ( 32 males and 13 females). Subjects ranged in age from 30 to 84 years, with the mean age being $45(\mathrm{SD} \pm 12)$. Subject characteristics are described in detail in Table 1. The study had two exclusion criteria: subjects who had diagnosed pulmonary disease and/or subjects who were currently being treated for OSA were excluded from the study. There were no exclusion criteria on the basis of age, sex, or health history. All methods and procedures, approved by the Institutional Review Boards of James Madison University, Radford University, Rockingham Memorial Hospital and Carilion Roanoke Community Hospital, were explained to the subjects, who then signed a written informed consent form.

Baseline Assessment

On the first day of CR, subjects returned with their completed Informed Consent and the ESS. The ESS has been shown to distinguish normal patients from patients with various sleep related disorders, such as OSA, narcolepsy, and idiopathic hyperinsonmia [32]. In patients with OSA, a significant correlation has been reported between ESS 
scores, respiratory disturbance index, and minimium oxyhemoglobin saturation levels, confirmed through overnight polysomnography [32].

Subject height was measured with a stadiometer and weight was measured with an electronic scale. BMI was calculated from measured weight and height $\left(\mathrm{kg} / \mathrm{m}^{2}\right)$. Resting BP was measured manually using a sphygmomanometer and a stethoscope after the subject had been in the supine position for a minimum of 5-minutes.

$\underline{\text { Hemodynamic Measurement }}$

Resting PhysioFlow measurements were recorded for 10 minutes while subjects were in the supine position. The PhysioFlow (PhysioFlow PF-05 Lab1, NeuMeDx, Bristol, PA) is non-invasive, impedance cardiograph that measures and calculates various hemodynamic parameters. These parameters are measured from electrodes placed on the neck and chest that detect electrical and impedance changes in the thorax. The PhysioFlow measures HR, SV, CO, CI, systolic arterial pressure, diastolic arterial pressure, contractility index (CTi), EF, LV ejection time, end diastolic volume, systemic vascular resistance, and systemic vascular resistance index (SVRi) [33].

\section{6-Minute Walk Test}

All subjects performed a 6-minute walk test after resting PhysioFlow measurements [34]. The distance each subject walked in the 6 minutes was measured in feet. HR and rating of perceived exertion were recorded every minute of the test. Following the 6-minute walk test, subjects sat in a chair for a 5-minute recovery period. HR and BP were measured every minute of recovery. 


\section{Home Sleep Evaluation}

Subjects were then given an at-home apnea screening device (ApneaLink Plus, ResMed Corp., San Diego, CA) to screen for possible OSA. The ApneaLink Plus measures respiratory nasal airflow, snoring, blood oxygen saturation, heart rate, and respiratory effort during sleep. The ApneaLink Plus records partial or complete respiratory obstructions, duration of obstructions, lowest and highest heart rate measurements, lowest and highest blood oxygen saturation measurements, and it will record the time points that these events occur during sleep [35]. A copy of instructions on how to use the ApneaLink Plus was sent home with the patient.

ApneaLink reports were sent to a certified sleep technician to analyze the data. Based on technician report, subjects were divided into either an OSA group or a nonOSA group. Subjects were classified as having OSA if AHI $\geq 5$. Of the 45 subjects, 33 were classified as likely having OSA and 12 were classified as non-OSA. All subjects then participated in scheduled CR sessions at their respective hospital. Subjects completed an average of 25.6 $\pm 8.4 \mathrm{CR}$ sessions. The average stay in CR was between 23 months, with the least being 1 month and the most being 4 months. CR staff was blinded to the severity of OSA in each subject.

Follow-up Assessment

On the subjects' last day of CR participation, all hemodynamic variables were reassessed and the 6-minute walk test was repeated.

$\underline{\text { Statistical Analysis }}$

The statistical analysis program used for this study was the IBM SPSS Statistics version 20. A mixed design ANOVA analysis was used to analyze mean values of weight, 
BMI, physioflow variables, and 6-minute walk test results from baseline to follow-up. Group was the between subject factor (OSA and non-OSA) and time was the withinsubject factor (baseline and follow-up). In cases where significance was found for the Mauchly's test of sphericity (cardiac index, ejection fraction, contractility index, and systemic vascular resistance), the Greenhouse-Geisser correction factor was used to adjust the $F$-test accordingly and its significance accordingly. All data are presented mean \pm the standard deviation. The statistical significance for all tests was set $a$ priori at $p<0.05$.

\section{RESULTS}

\section{$\underline{\text { Subject Characteristics }}$}

Baseline characteristics for each group are presented in Table 1. From baseline to follow-up, both groups had a significant reduction in BMI regardless of the presence of OSA $(p=0.046)$. Both groups had a significant main effect for time in 6-minute walk test performance from baseline to follow-up $(p=0.000)$. A significant main effect for group was also observed, as the OSA group had significantly higher values across both time points $(p=0.018)$. There was no significant effect for time or group by time with respect to age, HR, systolic arterial pressure, or diastolic arterial pressure.

\section{PhysioFlow Measurements}

PhysioFlow measurements before and after CR participation for each group are presented in Table 2. There was no significant effect for time or group by time with respect to $\mathrm{SV}, \mathrm{CO}, \mathrm{LV}$ ejection time, end diastolic volume, and systemic vascular resistance. There was a significant main effect for group observed in several resting variables. The OSA group had significantly lower CI ( $p=0.018)$, EF ( $p=0.039)$, and CTi 
$(p=0.008)$ and a significantly higher SVRi when compared to the non OSA group at both time points $(p=0.027)$.

\section{DISCUSSION}

The main finding of this study is that, in either group, hemodynamic variables did not significantly change from the beginning to the end of CR. This finding contradicts our hypothesis that subjects with untreated OSA would have diminished hemodynamic improvements at the completion of CR when compared to their non-OSA counterparts. Although the CR intervention did not improve resting hemodynamic variables, there are some novel findings of this study. CI, EF, and CTi values were significantly lower and SVRi values were significantly higher in the OSA group regardless of the CR intervention, which may indicate that the resting cardiac physiology differs between the two groups. The index values standardize these variables by removing the effect of varying body surface areas among subjects; for example, CI is equal to cardiac output relative to body surface area. The findings of this study suggest that the presence of untreated OSA may manifest disease specific cardiovascular alterations and may impact overall cardiac performance.

CTi represents the maximal velocity of ejected blood flow and is a good surrogate for contractility. CTi can be derived from pressure-volume relationships that depict the effectiveness of the heart to pump against the peripheral resistance. Specific variables of interest for CTi include EF and afterload stress [36]. In the present study, the decrease in EF coupled with the increase in SVRi may contribute to the overall decrease in the contractile state, $\mathrm{CT}$, of the myocardium. These alterations might be a reflection of an increased demand on the heart to overcome a greater peripheral resistance with each 
cardiac cycle. The decrease in CTi observed in the subjects with OSA may be a result of chronic exposure to pressure and volume changes that occur at the end of apneic events. When apneas are terminated, the withdrawal of sympathetic discharge results in a rapid increase in venous return and a significant increase in $\mathrm{CO}[4,9]$. $\mathrm{CO}$ increases before peripheral vasodilation occurs, resulting in large increases in BP [4]. Over time, these pressure changes could lead to cardiac remodeling. Martinka et al observed how cardiac structure is affected by high blood pressure variability in normotensive rats. Twelve weeks of exposure to large surges in BP evoked cardiac hypertrophy and decreased LV contractility index [37]. The pressure overload promoted collagen synthesis and deposition into the myocardium of the rats, contributing to cardiac hypertrophy and increased LV stiffness. The authors further speculated that the decrease in LV contractility was a result of decreased calcium transit [37]. Patients with untreated OSA have been shown to have an increased incidence of left atrial enlargement, right atrial enlargement, LV hypertrophy, and RV hypertrophy [11, 30, 38]. Given that the study subjects were middle-aged, mean age $65 \pm 12$ years, it is possible that they have had significant OSA for some time prior to it being identified. This would result in prolonged exposure to intermittent pressure and volume changes during apneic events that could lead to structural remodeling of the myocardium and the decrease in the CTi observed. Subjects in the OSA group had lowered CI when compared to the non-OSA group. This contradicts the findings of Kaleth et al [21] and Romero-Corral et al [11], who found no difference in CI between OSA and control subjects. Kaleth et al observed the cardiopulmonary response to exercise testing in healthy, inactive OSA subjects, mean age 45.6 \pm 10.7 years, compared to similarly matched controls. Prior to exercise testing, 
subjects with OSA did not have significantly different resting CI when compared to the control subjects [21]. Romero-Corral et al studied right and left ventricular performance in middle-aged subjects with mild, moderate, and severe OSA. Subjects with coronary artery disease were included in the sample; however, some exclusion criteria were cardiac surgery, presence of a permanent pacemaker, or moderate to severe valvular disease. In all subjects with OSA, regardless of disease severity, CI was not significantly different then control subjects [11]. The subjects in the present study were, on average, older than the subjects of the aforementioned studies, and were recently diagnosed with significant CVD.

Cardiac output is equivalent to HR multiplied by SV. Factors that influence SV are end diastolic volume and end systolic volume, with end systolic volume being the volume of blood in the ventricle at the end of contraction [39]. Although the PhysioFlow did not estimate this variable, components that effect end systolic volume are myocardial contractility and LV afterload [39]. The decrease in CTi, EF, and the increase in SVRi observed in the OSA group could represent an overall reduction in the volume of blood being pumped through the ventricles with each cardiac cycle. Ultimately, this would contribute to the reduction in CI observed.

The present finding of lowered EF in subjects with OSA has not been consistently confirmed. Romero et al [11] observed right and left ventricular performance in 27 control subjects, 18 subjects with mild OSA, and 40 subjects with moderate- to-severe OSA using Doppler echocardiography. The study reported impaired global RV performance, LV performance, and an increased left atrial volume index across all degrees of OSA severity; however, EF was preserved. The control group had an average 
EF of 61.6 \pm 6.2 and the moderate to severe OSA group had an average EF of $62.3 \pm 6.5$.

Other studies show similar EF preservation [30, 40]; however, in all studies, subjects with known CVD or ventricular dysfunction were excluded. Nahmias et al [41] observed right and left ventricular dysfunction in obese subjects with OSA, with dysfunction defined as a RV EF $<40 \%$ and LV EF $<50 \%$. In the presence of RV dysfunction, subjects with OSA had RV EF of $31 \pm 1$ and LV EF of $55 \pm 2$ when compared to subjects without OSA, $44 \pm 2$ and $65 \pm 2$ respectively. Similar results were seen in the present study where, at both time points, subjects with OSA had significantly lowered EF when compared to subjects without OSA. Although the values in this study and prior studies were within normal EF range and do not signify a clinically depressed EF, subjects with OSA appear to have lower EF when compared to their non-OSA counterparts.

An increased SVRi was observed in the OSA group when compared to the nonOSA group even in the absence of BP differences. Several mechanisms associated with untreated OSA promote an increase in vasoconstriction. Patients with OSA have increased nighttime and daytime sympathetic nerve activity $[4,5]$, increased plasma norepinephrine (NE) levels [5], and increase endothelin [42, 43] when compared to normal controls; all three of which contribute to peripheral vasoconstriction [42, 44]. Furthermore, circulating levels of nitric oxide (NO), a potent vasodilator, are suppressed in patients with OSA $[45,46]$. The chronic exposure to increased pressure on the endothelium could lead to a decrease in NO biosynthesis, endothelial dysfunction [46], and hypertension. It has been reported that the renin-angiotensin-aldosterone system is upregulated in patients with OSA as well $[42,43,47]$. This process increases vasoconstriction, promotes sodium reabsorption, and raises BP. The renin secretion can 
be stimulated through renal hypoxia or through increased sympathetic activity, which is chronically elevated in patients with OSA $[42,47]$. Because medications were not controlled for in the present study, it is possible that the use of hypertension medications among subjects accounted for the fact that there was no observed difference in BP. However, the various mechanisms of OSA induced vasoconstriction may contribute to the increased SVRi observed, without an overall increase in BP. Mean arterial pressure, the flow of blood through the aorta and its arteries, is equal to $\mathrm{CO}$ multiplied by vascular resistance [48]. It is possible that the decrease in CI coupled with the increase in SVRi resulted in no net change in pressure.

A secondary finding in the present study is that all subjects, regardless of the presence of OSA, improved BMI and improved 6-minute walk test performance by the end of CR. Although statistically significant, the improvement in BMI was relatively small, mediated by little weight loss. Caution should also be used when interpreting the improved 6-minute walk test results. Although used as a tool to assess functional capacity, there is considerable variability in 6-minute walk test performance between repeated trials, possibly due to increased familiarization $[49,50]$. It is recommended that subjects perform at least two 6-minute walk tests at baseline to get an accurate representation of initial exercise capacity and to track change over time [50]. For this study, subjects only performed one 6-minute walk test at baseline and at follow-up. Familiarization or improved self-efficacy could have contributed to the significant changes in test performance between time points. Therefore, it cannot be said with certainty that all subjects significantly improved fitness levels over the course of CR. 
It is of particular interest that this study did not report any significant changes in resting hemodynamic variables, regardless of OSA. Subjects in the current study completed an average of $25.6 \pm 8.4 \mathrm{CR}$ sessions. This resulted in an average stay in $\mathrm{CR}$ between 2-3 months, with the least being 1 month and the most being 4 months. Previous findings suggest that elderly subjects can improve resting hemodynamics variables with moderate to vigorous aerobic training in the absence of CVD $[51,52]$ and it has been reported that $\mathrm{CR}$ participation ranging from 3 to 6 months can improve physical fitness in patients [14]. However, patients in a CR program typically attend roughly 3 CR sessions per week and are generally exercising at a moderate intensity level. To our knowledge, this is the first study of its kind to observe resting hemodynamic variables in CR patients. Given that resting variables did not change in either group, it is possible that current CR exercise programs do not provide a large enough volume or a high enough intensity of aerobic activity to elicit significant changes in patients. This finding has practical significance in that the length of stay in a CR program may not be long enough for patients to attain cardiovascular benefits.

There are a few limitations to the present study. First, the sample size was relatively small. A larger subject sample would better allow us to analyze findings relative to each CVD diagnosis (MI, coronary artery bypass surgery, etc.). Second, no control was made for any medications that subjects were taking. Given that subjects recently underwent a significant CVD event (as evidenced by their referral to CR), it is likely that all subjects were taking at least one prescribed medication, which may have an impact on hemodynamic measures. However, the nature of this study allowed for an 
accurate representation of the standard CR patient, given that patients are not typically taken off their medications once admitted to a CR program.

The findings of the present study do have clinically relevant importance. Previous data suggests that $43 \%$ of patients entering a CR program may be undiagnosed and untreated for OSA [13]. The present study had a sample of $73.3 \%$ subjects having evidence for OSA, suggesting that prevalence of undiagnosed OSA in a CR population may be higher than previously estimated. Furthermore, the subjects with untreated OSA appear to have a decrease in cardiac performance, manifesting through the decrease in $\mathrm{CTi}$, the decrease in CI, the decrease in EF, and the increase in SVRi. This may indicate disease specific cardiovascular alterations. Epidemiological evidence suggests a causal relationship between the presence of OSA and CVD development [53], with severity of OSA having a strong association with CVD risk and all cause mortality [12, 54-57]. With the goals of CR programs being to reduce the risk of a secondary fatal MI and overall mortality $[14,15]$, these findings stress the importance of screening, diagnosing and treating OSA in a CR setting.

In conclusion, this study did not reveal a significant change in resting hemodynamic variables from the beginning to the end of CR, regardless of the presence of OSA. Subjects with untreated OSA, however, did have depressed CI, CTi, and EF and an increased SVRi at both time points when compared to subjects without OSA. This would suggest that patients with untreated OSA have a decrease in cardiac function that may be a result of chronic exposure to vascular and hemodynamic fluctuations that occur during apneic events. 


\section{Manuscript References}

1. Punjabi NM (2008) The epidemiology of adult obstructive sleep apnea. Proceedings of the American Thoracic Society 5:136-43.

2. Caples S, Gami A, Somers V (2005) Obstructive sleep apnea. Annals of Internal Medicine 142:187-97.

3. Somers V, White D, Amin R, et al. (2008) Sleep Apnea and Cardiovascular Disease: An American Heart Association/American College of Cardiology Foundation Scientific Statement From the American Heart Association Council for High Blood Pressure Research Professional Education Committee, Council on. Circulation 118:1080-1111.

4. Somers V, Dyken M, Clary M, Abboud F (1995) Sympathetic neural mechanisms in obstructive sleep apnea. The Journal of Clinical Investigation 96:1897-904.

5. Carlson J, Hedner J, Elam M, et al. (1993) Augmented resting sympathetic activity in awake patients with obstructive sleep apnea. Chest 103:1763-1768.

6. Imadojemu V, Gleeson K, Gray K (2002) Obstructive apnea during sleep is associated with peripheral vasoconstriction. American Journal of Respiratory and Critical Care Medicine 165:61-66.

7. Golbin J, Somers V, Caples S (2008) Obstructive sleep apnea, cardiovascular disease, and pulmonary hypertension. Proceedings of the American Thoracic Society 5:200-6.

8. Shamsuzzaman A, Gersh B, Somers V (2003) Obstructive Sleep Apnea: Implications for Cardiac and Vascular Disease. JAMA : The Journal of the American Medical Association 290:1906-1914.

9. Guilleminault C, Motta J, Mihm F, Melvin K (1986) Obstructive sleep apnea and cardiac index. Chest 89:331-334.

10. Wolk R, Shamsuzzaman A, Somers V (2003) Obesity, sleep apnea, and hypertension. Hypertension 42:1067-74.

11. Romero-Corral A, Somers V, Pellikka P, et al. (2007) Decreased right and left ventricular myocardial performance in obstructive sleep apnea. Chest 132:1863-70.

12. Marshall NS, Wong KKH, Liu PY, et al. (2008) Sleep apnea as an independent risk factor for all-cause mortality: the Busselton Health Study. Sleep 31:1079-85.

13. Sharma S, Parker AT (2011) Prevalence of obstructive sleep apnea in a patient population undergoing cardiac rehabilitation. Journal of Cardiopulmonary Rehabilitation and Prevention 31:188-92.

14. Leon AS, Franklin BA, Costa F, et al. (2005) Cardiac rehabilitation and secondary prevention of coronary heart disease: an American Heart Association scientific statement from the Council on Clinical Cardiology (Subcommittee on Exercise, Cardiac Rehabilitation, and Prevention) and the Council on Nut. Circulation 111:369-76.

15. Lavie CJ, Milani RV (1995) Effects of cardiac rehabilitation programs on exercise capacity, coronary risk factors, behavioral characteristics, and qualify of life in a large elderly cohort. The American Journal of Cardiology 76:177-179. 
16. Williams MA, Ades PA, Hamm LF, et al. (2006) Clinical evidence for a health benefit from cardiac rehabilitation: an update. American Heart Journal 152:835-41.

17. Kline CE, Crowley EP, Ewing GB, et al. (2011) The effect of exercise training on obstructive sleep apnea and sleep quality: a randomized controlled trial. Sleep 34:1631-40.

18. Awad KM, Malhotra A, Barnet JH, et al. (2012) Exercise is associated with a reduced incidence of sleep-disordered breathing. The American Journal of Medicine 125:485-90.

19. Servantes DM, Pelcerman A, Salvetti XM, et al. (2012) Effects of home-based exercise training for patients with chronic heart failure and sleep apnoea: a randomized comparison of two different programmes. Clinical Rehabilitation 26:45-57.

20. Ackel-D'Elia C, da Silva AC, Silva RS, et al. (2011) Effects of exercise training associated with continuous positive airway pressure treatment in patients with obstructive sleep apnea syndrome. Sleep and Breathing.

21. Kaleth AS, Chittenden TW, Hawkins BJ, et al. (2007) Unique cardiopulmonary exercise test responses in overweight middle-aged adults with obstructive sleep apnea. Sleep Medicine 8:160-8.

22. Tryfon S, Stanopoulos I, Dascalopoulou E, et al. (2004) Sleep apnea syndrome and diastolic blood pressure elevation during exercise. Respiration 71:499-504.

23. Vanuxem D, Badier M, Guillot C, et al. (1997) Impairment of muscle energy metabolism in patients with sleep apnoea syndrome. Respiratory Medicine 91:551-7.

24. Hargens TA, Guill SG, Zedalis D, et al. (2008) Attenuated heart rate recovery following exercise testing in overweight young men with untreated obstructive sleep apnea. Sleep 31:104-10.

25. Maeder MT, Ammann P, Schoch OD, et al. (2010) Determinants of postexercise heart rate recovery in patients with the obstructive sleep apnea syndrome. Chest 137:310-7.

26. Kline CE, Crowley EP, Ewing GB, et al. (2012) Blunted heart rate recovery is improved following exercise training in overweight adults with obstructive sleep apnea. International Journal of Cardiology.

27. Nishime EO, Cole CR, Blackstone EH, et al. (2000) Heart rate recovery and treadmill exercise score as predictors of mortality in patients referred for exercise ECG. JAMA : The Journal of the American Medical Association 284:1392-8.

28. Alchanatis M, Tourkohoriti G, Kosmas EN, et al. (2002) Evidence for left ventricular dysfunction in patients with obstructive sleep apnoea syndrome. European Respiratory Journal 20:1239-1245.

29. Laaban J-P, Pascal-Sebaoun S, Bloch E, et al. (2002) Left ventricular systolic dysfunction in patients with obstructive sleep apnea syndrome. Chest 122:1133-8.

30. Cloward TV, Walker JM, Farney RJ, Anderson JL (2003) Left ventricular hypertrophy is a common echocardiographic abnormality in severe obstructive sleep apnea and reverses with nasal continuous positive airway pressure. Chest 124:594-601.

31. Alonso-Fernández A, García-Río F, Arias M, et al. (2006) Obstructive sleep apnoea-hypoapnoea syndrome reversibly depresses cardiac response to exercise. European Heart Journal 27:207-15. 
32. Johns M (1991) A New Method for Measuring Daytime Sleepiness: The Epworth Sleepiness Scale. Sleep 14:540-545.

33. Charloux A, Lonsdorfer-Wolf E, Richard R, et al. (2000) A new impedance cardiograph device for the non-invasive evaluation of cardiac output at rest and during exercise: comparison with the "direct" Fick method. European Journal of Applied Physiology 82:313-20.

34. Rikli R, Jones C (1998) The reliability and validity of a 6-minute walk test as a measure of physical endurance in older adults. Journal of Aging and Physical Activity 6:363-375.

35. Chen H, Lowe A a, Bai Y, et al. (2009) Evaluation of a portable recording device (ApneaLink) for case selection of obstructive sleep apnea. Sleep and Breathing 13:213-9.

36. Kass D a., Beyar R (1991) Evaluation of contractile state by maximal ventricular power divided by the square of end-diastolic volume. Circulation 84:1698-1708.

37. Martinka P, Fielitz J, Patzak A, et al. (2005) Mechanisms of blood pressure variability-induced cardiac hypertrophy and dysfunction in mice with impaired baroreflex. American Journal of PhysiologyRegulatory, Integrative and Comparative Physiology 288:767-776.

38. Ahmed Q, Chung-Park M, Tomashefski JF (1997) Cardiopulmonary pathology in patients with sleep apnea/obesity hypoventilation syndrome. Human Pathology 28:264-269.

39. Sodums MT, Badke FR, Starling MR, et al. (1984) Evaluation of left ventricular contractile performance utilizing end- systolic pressure-volume relationships in conscious dogs. Circulation Research 54:731-739.

40. Arias M, García-Río F, Alonso-Fernández A, et al. (2005) Obstructive sleep apnea syndrome affects left ventricular diastolic function: effects of nasal continuous positive airway pressure in men. Circulation 112:375-83.

41. Nahmias J, Lao R, Karetzky M (1996) Right ventricular dysfunction in obstructive sleep apnoea: reversal with nasal continuous positive airway pressure. European Respiratory Journal 9:945-951.

42. Goodfriend TL, Calhoun D a (2004) Resistant hypertension, obesity, sleep apnea, and aldosterone: theory and therapy. Hypertension 43:518-24.

43. Phillips BG, Narkiewicz K, Pesek C a, et al. (1999) Effects of obstructive sleep apnea on endothelin-1 and blood pressure. Journal of Hypertension 17:61-6.

44. Harris KF, Matthews KA (2004) Interactions Between Autonomic Nervous System Activity and Endothelial Function: A Model for the Development of Cardiovascular Disease. Psychosomatic Medicine 66:153-164.

45. Ip MS, Lam B, Chan LY, et al. (2000) Circulating nitric oxide is suppressed in obstructive sleep apnea and is reversed by nasal continuous positive airway pressure. American Journal of Respiratory and Critical Care Medicine 162:2166-71.

46. Schulz R, Schmidt D, Blum A, et al. (2000) Decreased plasma levels of nitric oxide derivatives in obstructive sleep apnoea: response to CPAP therapy. Thorax 55:1046-51. 
47. Møller D, Lind P, Strunge B, Pedersen E (2003) Abnormal vasoactive hormones and 24-hour blood pressure in obstructive sleep apnea. American Journal of Hypertension 16:274-280.

48. Sesso HD, Stampfer MJ, Rosner B, et al. (2000) Systolic and Diastolic Blood Pressure, Pulse Pressure, and Mean Arterial Pressure as Predictors of Cardiovascular Disease Risk in Men. Hypertension 36:801-807.

49. Troosters T, Gosselink R, Decramer M (1999) Six minute walking distance in healthy elderly subjects. The European Respiratory Journal : Official Journal of the European Society for Clinical Respiratory Physiology 14:270-4.

50. Alison JA, Kenny P, King MT, et al. (2012) Repeatability of the Six-Minute Walk Test and Relation to Physical Function in Survivors of a Critical Illness. Physical Therapy 92:1556-1563.

51. Stratton JR, Levy WC, Cerqueira MD, et al. (1994) Cardiovascular Responses to Exercise Effects of Aging and Exercise Training in Healthy Men. Circulation 89:1648-1655.

52. Spina R, Ogawa T, Kohrt W, et al. (1993) Differences in cardiovascular adaptations to endurance exercise training between older men and women. Journal of Applied Physiology 75:849-855.

53. Kasai T, Floras JS, Bradley TD (2012) Sleep apnea and cardiovascular disease: a bidirectional relationship. Circulation 126:1495-510.

54. Shahar E, Whitney CW, Redline S, et al. (2001) Sleep-disordered breathing and cardiovascular disease: cross-sectional results of the Sleep Heart Health Study. American Journal of Respiratory and Critical Care Medicine 163:19-25.

55. Nieto F, Young T, Lind B, et al. (2000) Association of sleep-disordered breathing, sleep apnea, and hypertension in a large community-based study. Medical Association 283:1829-1836.

56. Young T, Finn L, Peppard PE, et al. (2008) Sleep disordered breathing and mortality: eighteen-year follow-up of the Wisconsin sleep cohort. Sleep 31:1071-8.

57. Yaggi HK, Concato J, Kernan WN, et al. (2005) Obstructive sleep apnea as a risk factor for stroke and death. The New England Journal of Medicine 353:2034-41. 
Table 1- Patient Characteristics

\begin{tabular}{lcc}
\hline \hline OSA $(\mathrm{n}=33)$ & Baseline & Follow-Up \\
\hline \hline AHI & $17.2 \pm 12.3$ & ---- \\
Age (years) & $65.0 \pm 12.4$ & $65.0 \pm 12.4$ \\
BMI $\left(\mathrm{kg} / \mathrm{m}^{2}\right)$ & $31.4 \pm 6.9$ & $31.1 \pm 6.8^{*}$ \\
Heart Rate (bpm) & $64.1 \pm 11.9$ & $59.4 \pm 8.0$ \\
Systolic Arterial Pressure (mmHg) & $121.3 \pm 14.4$ & $121.0 \pm 14.3$ \\
Diastolic Arterial Pressure (mmHg) & $75.1 \pm 10.7$ & $71.9 \pm 8.7$ \\
6 Minute Walk Test (feet) $§$ & $1491.6 \pm 267.6$ & $1742.4 \pm 254.3^{*}$ \\
& & \\
\hline \hline Non-OSA (n=12) & Baseline & Follow-Up \\
\hline \hline AHI & $1.8 \pm 1.3$ & ---- \\
Age (years) & $63.7 \pm 11.2$ & $63.7 \pm 11.2$ \\
BMI (kg/m $\left.{ }^{2}\right)$ & $28.7 \pm 4.1$ & $28.3 \pm 4.0^{*}$ \\
Heart Rate (bpm) & $65.5 \pm 12.3$ & $64.3 \pm 8.5$ \\
Systolic Arterial Pressure $(\mathrm{mmHg})$ & $126.6 \pm 24.4$ & $130.2 \pm 17.2$ \\
Diastolic Arterial Pressure $(\mathrm{mmHg})$ & $72.0 \pm 10.2$ & $69.3 \pm 7.7$ \\
6 Minute Walk Test (feet) & $1223.4 \pm 357.0$ & $1436.3 \pm 404.9^{*}$ \\
\hline \hline
\end{tabular}

Data are presented as mean $\pm \mathrm{SD}$.

*Significant $(p<0.05)$ main effect for time.

$\S$ Significant $(p<0.05)$ main effect for group. 
Table 2- PhysioFlow Measurements

\begin{tabular}{|c|c|c|}
\hline OSA & Baseline & Follow-Up \\
\hline Stroke Volume (mL/beat) & $70.0 \pm 29.0$ & $79.0 \pm 28.3$ \\
\hline Cardiac Output (L/min) & $4.4 \pm 1.7$ & $4.7 \pm 1.8$ \\
\hline Cardiac Index $\left(\mathrm{L} / \mathrm{min} / \mathrm{m}^{2}\right) \S$ & $2.1 \pm 0.7$ & $2.2 \pm 0.7$ \\
\hline Ejection Fraction $(\%) \S$ & $57.2 \pm 11.2$ & $59.6 \pm 11.7$ \\
\hline LV Ejection Time (msec) & $290.1 \pm 76.2$ & $310.0 \pm 63.6$ \\
\hline Contractility Index $\S$ & $105.2 \pm 44.0$ & $127.8 \pm 53.3$ \\
\hline End Diastolic Volume (mL) & $120.1 \pm 31.8$ & $134.8 \pm 54.9$ \\
\hline Systemic Vascular Resistance $\left(\mathrm{dyn} \cdot \mathrm{s} / \mathrm{cm}^{5}\right)$ & $1772.5 \pm 863.4$ & $1594.9 \pm 623.7$ \\
\hline $\begin{array}{l}\text { Systemic Vascular Resistance Index } § \\
\left(\mathrm{dyn} \cdot \mathrm{s} / \mathrm{cm}^{5}\right)\end{array}$ & $3730.2 \pm 1852.4$ & $3357.2 \pm 1417.1$ \\
\hline Non-OSA & Baseline & Follow-Up \\
\hline Stroke Volume (mL/beat) & $78.1 \pm 14.3$ & $78.7 \pm 14.3$ \\
\hline Cardiac Output (L/min) & $5.0 \pm 1.0$ & $5.0 \pm 0.8$ \\
\hline Cardiac Index $\left(\mathrm{L} / \mathrm{min} / \mathrm{m}^{2}\right)$ & $2.6 \pm 0.7$ & $2.6 \pm 0.4$ \\
\hline Ejection Fraction (\%) & $65.4 \pm 9.5$ & $65.4 \pm 10.4$ \\
\hline LV Ejection Time (msec) & $280.2 \pm 87.3$ & $280.3 \pm 44.6$ \\
\hline Contractility Index & $162.1 \pm 55.7$ & $160.7 \pm 75.5$ \\
\hline End Diastolic Volume (mL) & $121.4 \pm 32.0$ & $122.5 \pm 25.8$ \\
\hline Systemic Vascular Resistance $\left(\mathrm{dyn} \cdot \mathrm{s} / \mathrm{cm}^{5}\right)$ & $1373.4 \pm 255.7$ & $1351.2 \pm 202.5$ \\
\hline $\begin{array}{l}\text { Systemic Vascular Resistance Index } \\
\left(\text { dyn } \cdot \mathrm{s} / \mathrm{cm}^{5}\right)\end{array}$ & $2690.2 \pm 381.7$ & $2660.8 \pm 507.4$ \\
\hline
\end{tabular}

Data are presented as mean \pm SD.

$\S$ Significant $(p<0.05)$ main effect for group. 
Appendix A

Informed Consent 


\author{
James Madison University/Rockingham Memorial Hospital \\ Department of Kinesiology/Cardiac Rehabilitation Department \\ Informed Consent
}

\title{
Purpose
}

You are being asked to take part in a research study conducted by Dr. Trent Hargens from James Madison University entitled, "The impact of obstructive sleep apnea on cardiac rehabilitation participation" because you are admitted in the Cardiac Rehabilitation Program at Rockingham Memorial Hospital.

The primary goal of this study is to examine whether the presence of obstructive sleep apnea may impact the benefits of participating in Cardiac Rehabilitation.

Experimental Procedures

\section{At Rockingham Memorial Hospital}

Once admitted into the Carilion Cardiac Rehabilitation Program, you will be asked to participate in this study during your orientation visit. After the Informed Consent is signed, investigators will ask you to complete 2 one-page questionnaires to determine your risk of sleep apnea. In addition, a cardiac test will be offered to you. For this, you will be asked to lie down and relax, as 5 ECG electrodes will be placed on you to monitor the heart function. This is non-invasive and does not cause any harm.

You will also be asked to complete a six-minute walk test around the indoor track of the Cardiac Rehabilitation facility. This is a standard test done in this setting, and you will be asked to walk as far as you can in six minutes. Your heart rate and rhythm will be monitored throughout the test. This test will not be any harder than any of the exercise you will do during Cardiac Rehabilitation.

To better screen for sleep apnea, every patient will be provided with an at-home sleeptesting device. One of the researchers will teach you about setting up and using the small picket-sized recorder (the ApneaLink). It is equipped with straps, a finger probe, and a nasal cannula. You will be asked to wear this device for one entire night at home while you sleep. It measures your breathing activity, heart rate, and blood oxygen levels. The ApneaLink is a harmless monitor sometimes used by sleep doctors to screen people who may need more medical tests for possible nighttime breathing disorders. The researcher will make plans for you to take the device home, assist you by phone if needed to properly set it up, and make plans for you to return it the next time you come to Cardiac Rehabilitation.

The same night you wear the ApneaLink device, you will also be asked to wear a device called an accelerometer. This device will be worn around the wrist, on the arm that you do not write with. It is about the size of a large wristwatch. It is harmless and is used to measure your movement while you sleep. You will need to record the time you go to bed, 
as well as the time you get out of bed. There will be no setup of this device, other than to make sure it is on your wrist before you go to bed.

The total time commitment for the tests described here will be about 25 minutes, in addition to the normal Cardiac Rehabilitation orientation activity.

You will then begin your participation in Cardiac Rehabilitation. Upon completion of the program, you will be asked to repeat the cardiac test and six-minute walk on your last day of Cardiac Rehabilitation.

\section{At James Madison University}

In addition to the test being done at Rockingham Memorial Hospital, you will be asked if you are willing to undergo one additional test, to be done at the Human Performance Laboratory, on the campus of James Madison University, in Godwin Hall room 209. This is an optional part of the study, and if you do not agree to this portion of the study, you will not be excluded from the rest of the study or from participating in Cardiac Rehabilitation.

If you agree to this portion of the study, you will be asked to lie down in a quiet, darkened room for 10 minutes, after which an ultrasound probe (with gel) will be placed on your leg and arm to get images of your blood vessels. After this, a blood pressure cuff will be placed on your arm and inflated for a period of 5 minutes. After 5 minutes, the blood pressure cuff will be released we will again collect ultrasound images of the blood vessel in your arm. We will collect images for 2 minutes after we release the blood pressure cuff. We will then repeat this procedure for your leg. If at any point during the 5 minutes that the blood pressure cuff is on your leg or arm that you feel you need to stop the test, the researcher will immediately deflate the cuff. This portion of the study will require about $30-45$ minutes of your time.

Once you are done with Cardiac Rehabilitation, you will be asked to return again to James Madison University and complete this test again, if you did these tests at the beginning.

\section{Risks}

There are no more than minimal risks associated with the questionnaire, wearing the ApneaLink device, or wearing an accelerometer. However, there is some risk associated with the ultrasound measurements and six-minute walk test.

The risks of the ultrasound blood pressure cuff procedure include discomfort often described as your arm is "falling asleep"; there is a temporary reduction or loss of feeling because the blood flow through the vessel is stopped for five minutes. There is no longterm risk associated with this procedure. If, during the test, you feel that you cannot tolerate the discomfort, it will be immediately stopped. In the unlikely event of cardiac 
or other complications during the ultrasound test, an emergency plan is in place. This includes immediate access to a phone to call emergency personnel. In addition, each of the investigators is CPR certified. You will not be doing anything strenuous during this test. You will be at rest and lying down throughout the test.

There is a risk of abnormal responses during the six-minute walk test. These changes may include abnormal blood pressure, fainting, heart rhythm disorders, stroke, heart attack, and death. The chance of serious heart problems during maximal exercise among adults is very small (less than 1/10,000 maximal exercise tests). You will be continuously monitored by researchers and Cardiac Rehabilitation staff throughout the test. The Cardiac Rehabilitation program has written emergency procedures to address exercise-related complications during this test, as well as during your participation in Cardiac Rehabilitation.

Benefits

There is no guarantee that you will get any benefit from taking part in this study. Benefits may include knowledge about your health status. The questionnaires and athome sleep test will provide you with information concerning your risk for possible sleep apnea. Copies of the cardiac and sleep tests will be provided to you and you can decide to share these with your doctor. You will be referred to an appropriate health care professional, if necessary, based on your individual results. All costs related to follow-up appointments with these doctors, including further sleep evaluation, will be your responsibility and not the responsibility of James Madison University or Rockingham Memorial Hospital. Indirect benefits of participating in this study will be helping the researchers to better understand how having sleep apnea may influence the benefits seen while participating in Cardiac Rehabilitation.

\section{Inquiries}

If you have any questions or concerns or you would like to receive a copy of the final aggregate results of this study, please contact Dr. Trent Hargens at hargenta@jmu.edu or (540) 568-5844. In the case of any immediate concerns or adverse reactions during the study, contact Dr. Hargens on his cell phone (540) 810-1310.

Questions about Your Rights as a Research Subject

Dr. David Cockley

Chair, Institutional Review Board

James Madison University

(540) 568-2834

cocklede@jmu.edu

Confidentiality 
All data and results will be kept confidential. You will be assigned an identification code. At no time will your name be identified with your individual data. The researcher retains the right to use and publish non-identifiable data. All data will be kept secured in a locked cabinet and password protected computer. Final aggregate results will be made available to participants upon request.

\section{Freedom of Consent}

Your participation is entirely voluntary. You are free to choose not to participate. Should you choose to participate, you can withdraw at any time without consequences of any kind.

I have read this consent form and I understand what is being requested of me as a participant in this study. I freely consent to participate. I have been given satisfactory answers to my questions. The investigator provided me with a copy of this form. I certify that I am at least 18 years of age.

$\overline{\text { Name of Subject (Printed) } \quad \text { Name of Researcher (Printed) }}$

Name of Subject (Signed) $\quad$ Name of Researcher (Signed)

Date Date 
Appendix B

Epworth Sleepiness Scale 


\section{Epworth Sleepiness Scale}

Subject ID Name

Date Completed

This questionnaire asks you to indicate the chances of you becoming drowsy during hours of the day that you are not in bed sleeping. "How likely are you to doze off or fall asleep in the following situations?"

Use the following scale and indicate the most appropriate number for each situation.

$$
\begin{aligned}
& 0=\text { would never doze } \\
& 1=\text { slight chance of dozing } \\
& 2=\text { moderate chance of dozing } \\
& 3=\text { high chance of dozing }
\end{aligned}
$$

\section{Situation}

1. Sitting and reading

2. Watching T.V.

3. Sitting, inactive in a public place (ex. Theatre or meeting)

4. As a passenger in a car for an hour without a break

5. Lying down to rest in the afternoon when circumstances permit

6. Sitting and talking with someone

7. Sitting quietly after a lunch without alcohol

8. In a car, while stopped for a few minutes in the traffic

\section{Chance of Dozing}

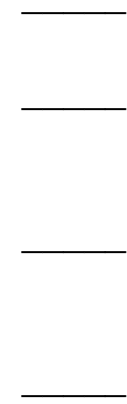


Appendix C

Data Collection Sheet 
Data Collection Sheet

Patient Code

Age

Height in/ cm Weight $\mathrm{lb} /$ $\mathrm{k}$

Date

6 minutes walk test

Abdominal circumference

Berlin Score

Epworth Score

Blood Pressure

Calculations (Resting Values)

Heart Rate (bpm)

Stroke Volume (ml)

Cardiac Index $\left(1 / \mathrm{min} / \mathrm{m}^{\wedge} 2\right)$

Systemic vascular resistance

Myocardial contractility

Notes:

Signature: 


\section{List of References}

1. Punjabi NM (2008) The epidemiology of adult obstructive sleep apnea. Proceedings of the American Thoracic Society 5:136-43.

2. Caples S, Gami A, Somers V (2005) Obstructive sleep apnea. Annals of Internal Medicine 142:187-97.

3. Somers V, White D, Amin R, et al. (2008) Sleep Apnea and Cardiovascular Disease: An American Heart Association/American College of Cardiology Foundation Scientific Statement From the American Heart Association Council for High Blood Pressure Research Professional Education Committee, Council on. Circulation 118:1080-1111.

4. Ancoli-Israel S, Kripke D, Klauber M, Mason W (1991) Sleep-disordered breathing in communitydwelling elderly. Sleep 14:486-495.

5. Bixler E, Vgontzas A, Ten Have T, et al. (1998) Effects of age on sleep apnea in men: I. Prevalence and severity. American Journal of Respiratory and Critical Care Medicine 157:144-8.

6. Tishler PV, Larkin EK, Schluchter MD, Redline S (2003) Incidence of sleep-disordered breathing in an urban adult population. JAMA: The Journal of the American Medical Association 289:2230.

7. Young T (2002) Epidemiology of Obstructive Sleep Apnea: A Population Health Perspective. American Journal of Respiratory and Critical Care Medicine 165:1217-1239.

8. Kasai T, Floras JS, Bradley TD (2012) Sleep apnea and cardiovascular disease: a bidirectional relationship. Circulation 126:1495-510.

9. Goodfriend TL, Calhoun D a (2004) Resistant hypertension, obesity, sleep apnea, and aldosterone: theory and therapy. Hypertension 43:518-24.

10. Wolk R, Shamsuzzaman A, Somers V (2003) Obesity, sleep apnea, and hypertension. Hypertension 42:1067-74.

11. Kuniyoshi FHS, Garcia-Touchard A, Gami AS, et al. (2008) Day-night variation of acute myocardial infarction in obstructive sleep apnea. Journal of the American College of Cardiology 52:343-6.

12. Lee C-H, Khoo S-M, Tai B-C, et al. (2009) Obstructive sleep apnea in patients admitted for acute myocardial infarction. Prevalence, predictors, and effect on microvascular perfusion. Chest 135:1488-95.

13. Konecny T, Kuniyoshi FHS, Orban M, et al. (2010) Under-diagnosis of sleep apnea in patients after acute myocardial infarction. Journal of the American College of Cardiology 56:742-3.

14. Shahar E, Whitney CW, Redline S, et al. (2001) Sleep-disordered breathing and cardiovascular disease: cross-sectional results of the Sleep Heart Health Study. American Journal of Respiratory and Critical Care Medicine 163:19-25.

15. Marshall NS, Wong KKH, Liu PY, et al. (2008) Sleep apnea as an independent risk factor for all-cause mortality: the Busselton Health Study. Sleep 31:1079-85.

16. Nieto F, Young T, Lind B, et al. (2000) Association of sleep-disordered breathing, sleep apnea, and hypertension in a large community-based study. Medical Association 283:1829-1836. 
17. Young T, Finn L, Peppard PE, et al. (2008) Sleep disordered breathing and mortality: eighteen-year follow-up of the Wisconsin sleep cohort. Sleep 31:1071-8.

18. Yaggi HK, Concato J, Kernan WN, et al. (2005) Obstructive sleep apnea as a risk factor for stroke and death. The New England Journal of Medicine 353:2034-41.

19. Davies RJ, Ali NJ, Stradling JR (1992) Neck circumference and other clinical features in the diagnosis of the obstructive sleep apnoea syndrome. Thorax 47:101-5.

20. White D (2006) Sleep apnea. Proceedings of the American Thoracic Society 3:124-8.

21. Somers V, Dyken M, Clary M, Abboud F (1995) Sympathetic neural mechanisms in obstructive sleep apnea. The Journal of Clinical Investigation 96:1897-904.

22. Imadojemu V, Gleeson K, Gray K (2002) Obstructive apnea during sleep is associated with peripheral vasoconstriction. American Journal of Respiratory and Critical Care Medicine 165:61-66.

23. Carlson J, Hedner J, Elam M, et al. (1993) Augmented resting sympathetic activity in awake patients with obstructive sleep apnea. Chest 103:1763-1768.

24. Golbin J, Somers V, Caples S (2008) Obstructive sleep apnea, cardiovascular disease, and pulmonary hypertension. Proceedings of the American Thoracic Society 5:200-6.

25. Shamsuzzaman A, Gersh B, Somers V (2003) Obstructive Sleep Apnea: Implications for Cardiac and Vascular Disease. JAMA : The Journal of the American Medical Association 290:1906-1914.

26. Buda A, Pinsky M, Ingels N (1979) Effect of intrathoracic pressure on left ventricular performance. The New England Journal of Medcine 301:453-459.

27. Guilleminault C, Motta J, Mihm F, Melvin K (1986) Obstructive sleep apnea and cardiac index. Chest 89:331-334.

28. Jelic S, Lederer DJ, Adams T, et al. (2010) Vascular inflammation in obesity and sleep apnea. Circulation 121:1014-21.

29. Harris KF, Matthews KA (2004) Interactions Between Autonomic Nervous System Activity and Endothelial Function: A Model for the Development of Cardiovascular Disease. Psychosomatic Medicine 66:153-164.

30. Ip MS, Lam B, Chan LY, et al. (2000) Circulating nitric oxide is suppressed in obstructive sleep apnea and is reversed by nasal continuous positive airway pressure. American Journal of Respiratory and Critical Care Medicine 162:2166-71.

31. Schulz R, Schmidt D, Blum A, et al. (2000) Decreased plasma levels of nitric oxide derivatives in obstructive sleep apnoea: response to CPAP therapy. Thorax 55:1046-51.

32. Punjabi NM, Beamer B (2007) C-reactive protein is associated with sleep disordered breathing independent of adiposity. Sleep 30:29-34.

33. Ryan S, Taylor CT, McNicholas WT (2005) Selective activation of inflammatory pathways by intermittent hypoxia in obstructive sleep apnea syndrome. Circulation 112:2660-7. 
34. Mehra R, Xu F, Babineau DC, et al. (2010) Sleep-disordered breathing and prothrombotic biomarkers: cross-sectional results of the Cleveland Family Study. American Journal of Repsiratory and Critical Care Medicine 182:826-33.

35. Hijmering M, Stroes E, Olijhoek J (2002) Sympathetic activation markedly reduces endotheliumdependent, flow-mediated vasodilation. Journal of the American College of Cardiology 39:4-9.

36. Kato M, Roberts-Thomson P, Phillips BG, et al. (2000) Impairment of Endothelium-Dependent Vasodilation of Resistance Vessels in Patients With Obstructive Sleep Apnea. Circulation 102:26072610.

37. Arias M, García-Río F, Alonso-Fernández A, et al. (2005) Obstructive sleep apnea syndrome affects left ventricular diastolic function: effects of nasal continuous positive airway pressure in men. Circulation 112:375-83.

38. Cloward TV, Walker JM, Farney RJ, Anderson JL (2003) Left ventricular hypertrophy is a common echocardiographic abnormality in severe obstructive sleep apnea and reverses with nasal continuous positive airway pressure. Chest 124:594-601.

39. Romero-Corral A, Somers V, Pellikka P, et al. (2007) Decreased right and left ventricular myocardial performance in obstructive sleep apnea. Chest 132:1863-70.

40. Guilleminault C, Connolly S (1983) Cardiac arrhythmia and conduction disturbances during sleep in 400 patients with sleep apnea syndrome. The American Journal of Cardiology 52:490-494.

41. Hoffstein V, Mateika S (1994) Cardiac arrhythmias, snoring, and sleep apnea. Chest 106:466-471.

42. Haider A, Larson M, Benjamin E, Levy D (1998) Increased left ventricular mass and hypertrophy are associated with increased risk for sudden death. Journal of the American College of Cardiology 32:1454-9.

43. Sharma S, Parker AT (2011) Prevalence of obstructive sleep apnea in a patient population undergoing cardiac rehabilitation. Journal of Cardiopulmonary Rehabilitation and Prevention 31:188-92.

44. Williams MA, Ades PA, Hamm LF, et al. (2006) Clinical evidence for a health benefit from cardiac rehabilitation: an update. American Heart Journal 152:835-41.

45. Leon AS, Franklin BA, Costa F, et al. (2005) Cardiac rehabilitation and secondary prevention of coronary heart disease: an American Heart Association scientific statement from the Council on Clinical Cardiology (Subcommittee on Exercise, Cardiac Rehabilitation, and Prevention) and the Council on Nut. Circulation 111:369-76.

46. Lavie CJ, Milani RV (1995) Effects of cardiac rehabilitation programs on exercise capacity, coronary risk factors, behavioral characteristics, and qualify of life in a large elderly cohort. The American Journal of Cardiology 76:177-179.

47. Milani RV, Lavie CJ, Mehra MR (2004) Reduction in C-reactive protein through cardiac rehabilitation and exercise training. Journal of the American College of Cardiology 43:1056-61.

48. Kaleth AS, Chittenden TW, Hawkins BJ, et al. (2007) Unique cardiopulmonary exercise test responses in overweight middle-aged adults with obstructive sleep apnea. Sleep Medicine 8:160-8. 
49. Tryfon S, Stanopoulos I, Dascalopoulou E, et al. (2004) Sleep apnea syndrome and diastolic blood pressure elevation during exercise. Respiration 71:499-504.

50. Vanuxem D, Badier M, Guillot C, et al. (1997) Impairment of muscle energy metabolism in patients with sleep apnoea syndrome. Respiratory Medicine 91:551-7.

51. Hargens TA, Guill SG, Zedalis D, et al. (2008) Attenuated heart rate recovery following exercise testing in overweight young men with untreated obstructive sleep apnea. Sleep 31:104-10.

52. Maeder MT, Ammann P, Schoch OD, et al. (2010) Determinants of postexercise heart rate recovery in patients with the obstructive sleep apnea syndrome. Chest 137:310-7.

53. Kline CE, Crowley EP, Ewing GB, et al. (2012) Blunted heart rate recovery is improved following exercise training in overweight adults with obstructive sleep apnea. International Journal of Cardiology.

54. Nishime EO, Cole CR, Blackstone EH, et al. (2000) Heart rate recovery and treadmill exercise score as predictors of mortality in patients referred for exercise ECG. JAMA : The Journal of the American Medical Association 284:1392-8.

55. Alonso-Fernández A, García-Río F, Arias M, et al. (2006) Obstructive sleep apnoea-hypoapnoea syndrome reversibly depresses cardiac response to exercise. European Heart Journal 27:207-15.

56. Ackel-D'Elia C, da Silva AC, Silva RS, et al. (2011) Effects of exercise training associated with continuous positive airway pressure treatment in patients with obstructive sleep apnea syndrome. Sleep and Breathing.

57. Awad KM, Malhotra A, Barnet JH, et al. (2012) Exercise is associated with a reduced incidence of sleep-disordered breathing. The American Journal of Medicine 125:485-90.

58. Kline CE, Crowley EP, Ewing GB, et al. (2011) The effect of exercise training on obstructive sleep apnea and sleep quality: a randomized controlled trial. Sleep 34:1631-40.

59. Alchanatis M, Tourkohoriti G, Kosmas EN, et al. (2002) Evidence for left ventricular dysfunction in patients with obstructive sleep apnoea syndrome. European Respiratory Journal 20:1239-1245.

60. Laaban J-P, Pascal-Sebaoun S, Bloch E, et al. (2002) Left ventricular systolic dysfunction in patients with obstructive sleep apnea syndrome. Chest 122:1133-8.

61. Johns M (1991) A New Method for Measuring Daytime Sleepiness: The Epworth Sleepiness Scale. Sleep 14:540-545.

62. Charloux A, Lonsdorfer-Wolf E, Richard R, et al. (2000) A new impedance cardiograph device for the non-invasive evaluation of cardiac output at rest and during exercise: comparison with the "direct" Fick method. European Journal of Applied Physiology 82:313-20.

63. Rikli R, Jones C (1998) The reliability and validity of a 6-minute walk test as a measure of physical endurance in older adults. Journal of Aging and Physical Activity 6:363-375.

64. Chen H, Lowe A a, Bai Y, et al. (2009) Evaluation of a portable recording device (ApneaLink) for case selection of obstructive sleep apnea. Sleep and Breathing 13:213-9. 
65. Cole R, Kripke D, Gruen W, et al. (1992) Techincal Note: Automatic Sleep/Wake Identification from Wrist Activity. Sleep 15:461-469.

66. Sadeh A, Hauri PJ, Kripke DF, Lavie P (1995) An American Sleep Disorders Association Review The Role of Actigraphy in the Evaluation of Sleep Disorders. Sleep 18:288-302. 